\title{
The substratum in Insular Celtic
}

\begin{abstract}
The discussion focuses on the problem of pre-Celtic substratum languages in the British Islands. The article by R. Matasović begins by dealing with the syntactic features of Insular Celtic languages (Brittonic and Goidelic): the author analyses numerous innovations in Insular Celtic and finds certain parallels in languages of the Afro-Asiatic macrofamily. The second part of his paper contains the analysis of that particular part of the Celtic lexicon which cannot be attributed to the PIE layer. A number of words for which only a substratum origin can be assumed is attested only in Brittonic and Goidelic. The author proposes to reconstruct Proto-Insular Celtic forms for this section of the vocabulary. This idea encounters objections from T. Mikhailova, who prefers to qualify common non-Celtic lexicon of Goidelic and Brittonic as parallel loanwords from the same substratum language. The genetic value of this language, however, remains enigmatic for both authors.
\end{abstract}

Keywords: Pre-Celtic substratum, Goidelic, Brittonic, Insular Celtic, classification of Celtic languages, etymology, reconstruction, loanwords, wandering words.

\section{Introduction}

We will never know which language or languages were spoken in the British Isles before the coming of the Celts. The Pictish language, very few documents of which have been preserved in the Ogam script, may actually have been Celtic (Forsyth 1997). If there ever was a pre-Celtic Pictish language, virtually nothing is known about its structure, to say nothing about its genetic affiliation. Moreover, the nature of Insular Celtic is a very debated issue. While some linguists consider it to be a genetic unit, i.e. a branch on the genealogical tree of Celtic languages (e.g. McCone 1996), others believe that the isoglosses shared by Goidelic and Brythonic are better interpreted as results of areal convergence between related, but already divergent branches of Celtic languages (Matasović 2007). The arguments in favour of an Insular Celtic branch rely on the fact that there are several features of Goidelic and Brythonic, especially in the domain of verbal inflexion, which have not so far been attested in Gaulish, Lepontic, and Celtiberian, and which seem to be common innovations of the Insular Celtic languages. The arguments in favour of regarding Insular Celtic as a Sprachbund rely on the fact that, although Goidelic and Brythonic do share a number of features, the application of the comparative method does not allow us to reconstruct a Proto-Insular-Celtic as different from Proto-Celtic itself (see Matasović 2007 for an extensive discussion).

Why is the pre-Celtic substratum of the British Isles relevant to the proper subdivision of the Celtic languages? In this paper we shall argue that the two proposed views of Insular Celtic make different predictions about the nature of the pre-Celtic substratum. If the speakers of Proto-Insular Celtic established contacts with speakers of the substratum language (or languages) in the British Isles, we would expect to find a considerable amount of non-IndoEuropean loanwords shared by both Goidelic and Brythonic, but lacking in other Celtic and Indo-European languages. If, on the other hand, the speakers of Goidelic and Brythonic ar- 
rived in the British Isles as linguistically differentiated groups, we would not expect the number of shared substratum words to be significant. ${ }^{1}$ The substratum might have shared a number of areally important typological features, which would be reflected in structural convergences in Brythonic and Goidelic, but there would be few, if any, common loanwords shared by these two Celtic Branches. The rest of this paper represents an attempt to see which of these two alternative hypotheses better fits the evidence.

\section{The syntactic evidence}

The syntactic parallels between Insular Celtic and Afro-Asiatic languages (which used to be called Hamito-Semitic) were noted more than a century ago by Morris-Jones (1899), and subsequently discussed by a number of scholars. ${ }^{2}$ These parallels include the following.

a) The VSO order, attested both in OIr. and in Brythonic from the earliest documents, cf. (1a) from Old Irish and (1b) from Berber (Ait Hassan dialect, cf. Sadiqi 1997: 148):

(1a) Beirid in fer in claideb

carry.3SG.PRES ART man.NOM.SG ART sword.ACC.SG

"The man carries the sword"

(1b) i-ara hmad tabrat

3sG-wrote Ahmed letter

"Ahmed wrote a letter"

b) The existence of special relative forms of the verb, cf. (2a) from Old Irish and (2b) from Ancient Egyptian (Isaac 2001: 154):

(2a) In claideb beires in fer

ART sword.NOM.SG carry.3SG.REL.PRES ART man.NOM.SG

"The sword that the man carries"

(2b) jr.t hrw ... jtj.t-k

eye of.horus take.REL.2SG

"The eye of Horus, which you should take"

c) The existence of prepositions inflected for person (or prepositional pronouns), e.g. OIr. dom "to me", duit "to you", dó "to him", etc., Ancient Egyptian jm-j "with me", jm-f "with him", etc.

\footnotetext{
${ }^{1}$ Other possibilities are also imaginable, of course, but they are less probable. It is possible that there was a Common Proto-Insular Celtic, but that it was spoken on the Continent, and that Goidelic and Brythonic arrived to the British Isles as already differentiated languages; moreover, it is possible that, although they were different languages, they both came in the contact with a single, homogenous substratum spoken in the whole of the British Isles, in which case we would again expect a substantial number of common loanwords shared by Brythonic and Goidelic. This latter possibility (a single substratum extending over Britain and Ireland) is a priori improbable considering the level of linguistic diversity those parts of prehistoric Europe for which we have more evidence (e.g. Spain and Italy).

2 E.g. Julius Pokorny (1949), who brought speculations about pre-Celtic substratum in Britain and Ireland to some disrepute by invoking parallels in Basque and (even) North Caucasian. By the time D. Greene wrote his paper on the "making of Insular Celtic" (Greene 1966) the hypothesis about non-IE substrates in the British Isles was very much out of fashion, and it remained so until its recent revival in the works of Gensler (1993) and Jongeling (2000), among others. For a hypothesis about another Nostratic (perhaps Altaic) substratum in Celtic see Mikhailova 2007.
} 
d) Prepositional progressive verbal forms, cf. (3a) from Old Irish and (3b) from Ancient Egyptian (Morris Jones 1899: 625):

(3a) At-tá in fer oc marbad a námat

is.3SG.PRES ART man.NOM.SG at killing his enemy.GEN.SG

"The man is killing his enemy"

(3b) áu-k em meh

be.2SG in filling

"You are filling"

e) The existence of the opposition between the "absolute" and "conjunct" verbal forms. The former are used when the verb is in the absolute initial position in the clause, and the latter when it is preceded by either a subordinator, or an operator changing the illocutionary force of the clause, cf. (4) from Old Irish: ${ }^{3}$

(4) in ferid in claideb.
carry.3SG.ABS.PRES ART man.NOM.SG ART sword.ACC.SG
Ní beir in scíath
NEG carry.3SG.CONJ.PRES ART shield.ACC.SG
"The man carries the sword. He does not carry the shield"

In Ancient Egyptian, a similar opposition exists between the emphatic and non-emphatic verbal forms, whereby the emphatic forms occur clause-initially, and the non-emphatic forms occur after certain particles, such as the negation $n n$. Thus, the verb 'to be' has the emphatic form $w n n$, and the non-emphatic form $w n$ after the negation (Isaac 2001: 158):

(5) $n n$ wn tp-f.
NEG be head-his
"He had no head"

The aforementioned features of Old Irish and Insular Celtic syntax (and a few others) are all found in Afro-Asiatic languages, often in several branches of that family, but usually in Berber and Ancient Egyptian (see e.g. Isaac 2001, 2007a).

Orin Gensler, in his unpublished dissertation (1993) applied refined statistical methods showing that the syntactic parallels between Insular Celtic and Afro-Asiatic cannot be attributed to chance. The crucial point is that these parallels include features that are otherwise rare cross-linguistically, but co-occur precisely in those two groups of languages. This more or less amounts to a proof that there was some connection between Insular Celtic and Afro-Asiatic at some stage in prehistory, but the exact nature of that connection is still open to speculation. Namely, it is not necessary to assume that the British Isles had been populated by speakers of Afro-Asiatic languages prior to the arrival of the Celts: they could also have been populated by speakers of unidentifiable, extinct languages which shared a number of typological characteristics with Afro-Asiatic due to their being spoken in the same macro-area encompasing prehistoric Western Europe and Northwestern Africa.

In this light, it is important to note that Insular Celtic also shares a number of areal isoglosses with languages of Western Africa, sometimes also with Basque, which shows that the

\footnotetext{
${ }^{3}$ This feature is attested only in the earliest forms of Old Welsh (by the Middle Welsh period it was already obsolete), and it is also not widespread in Afro-Asiatic, occurring only in Old Egyptian and its descendant, Coptic (Isaac 2001).
} 
Insular Celtic - Afroasiatic parallels should be viewed in light of the larger framework of prehistoric areal convergences in Western Europe and NW Africa.

1. The inter-dental fricative $/ \mathrm{p} /$, which is very rare cross-linguistically (according to WALS), is found very frequently in languages of Western Europe (including Insular Celtic languages, but also English, Icelandic, and Castillan Spanish), but also in many varieties of Berber (e.g. in Kabyle) and in several Atlantic languages of the Niger-Congo family in NW Africa (e.g. Balanta).

2. The initial consonant mutations, or regular alternations of initial consonants caused by the grammatical category of the preceding word, or the grammatical construction of the word in question, are extremely rare cross-linguistically. All Insular Celtic languages have this feature, cf. the following examples from Old Irish, where the possessive pronoun $a$ causes different consonant mutations of the head noun depending on its gender/number:

(5) a bó /a bo:/ 'her cow': a bó /a vo:/ 'his cow': a mbó /a mo:/ 'their cow'.

Interestingly, the same phenomenon is found in a number of Atlantic languages in NW Africa, including Fulbe, where the verbal root changes the initial consonant depending on the number of its subject (Koval' \& Zubko 1986):

(6) hoto o fahi? "Where did he go?": hoto be pahi 'where did they go?"

3. While the order demonstrative-noun (within the NP) is almost universal in the whole of Northern Eurasia (according to the data in WALS), in Insular Celtic we find the reverse order, cf. OIr. in fer sin 'that man', W y gzr hwnn 'id.'. The same order is found in Basque (etxe hau 'this house') and in most languages of the Atlantic group of Niger Congo languages in NW Africa (e.g. Wolof, Balanta, Ndut, Kisi, Temne, and others). The same order has spread also to a number of Berber languages (e.g. Chaouia, Rif), while in others the original postposed pronoun has become a demonstrative suffix on the nominal root (e.g. in Tashelhit).

4. The vigesimal counting system is clearly much less common in Eurasia than the decimal system, which can be posited for PIE. The Insular Celtic languages clearly stand out among the Indo-European languages in having clear traces of the vigesimal counting system (cf. OIr. ceithre fichit ' 80 ' = 'four twenties'), although in the historical period this system is not preserved in a pure form. It may be significant that a considerable number of Atlantic languages in NW Africa also have the vigesimal counting system (e.g. Diola-Fogny, Gola, and Fulbe, among others), and that it is also found in Basque.

5. While most languages of Central and Eastern Europe either lack demonstrative articles, or have suffixes expressing definiteness (as in most Balkan languages), preposed independent definite articles characterize most languages of Western Europe (including Ibero-Romance, French, English, but also all Insular Celtic languages). Interestingly, this type of definite article is also found in many Atlantic languages (Wolof, Balanta) and also some Mande languages of NW Africa (e.g. Bambara).

Of course, these parallels could also be accidental, and they are certainly not adduced in order to claim that there ever was a Basque or Atlantic substratum in the British Isles. They are only meant to show that areally significant features of Insular Celtic go beyond Afro-Asiatic.

\section{The lexical evidence}

Any student of the history of Old Irish and Middle Welsh is probably aware of the fact that many words in these languages do not have Indo-European etymology. My own "Etymologi- 
cal Dictionary of Proto-Celtic" (Matasović 2009), which is far from being complete, nevertheless contains the large majority of words that can be safely reconstructed for Proto-Celtic, and their number amounts to only 1490 items. Of these, only 85 do not have Indo-European etymology, which means that they can be considered to be of substratum origin. This amounts to less than $6 \%$ of the reconstructed Proto-Celtic lexicon. Now, only a minority of these 85 words are attested exclusively in the two groups of Insular Celtic languages, but not elsewhere. If all of those words with possible or probable cognates in Continental Celtic, or other IE languages are excluded, we are left with only 38 words shared by Brythonic and Goidelic without any plausible IE etymology. These words belong to the semantic fields that are usually prone to borrowing, including words referring to animals (e.g. PCelt. * $b l V d V$ - 'wolf, large predator', cf. OIr. bled 'monster, large animal, whale', W bleidd 'wolf, hero', OCo. bleit gl. lupus, PCelt. *lukot'mouse', cf. OIr. luch, MW llygod-en, OBret. loc, PCelt. *sido- 'elk, stag', cf. MIr. sed, MW hit, hyd, MBret. heizes 'hind, doe', PCelt. *sukko- 'pig', cf. OIr. socc 'snout, plough-share', MW hwch 'pig', OBret. hoch gl. aper, PCelt. *wesako- 'raven, grebe', cf. OIr. fíach 'raven', MW gwyach 'grebe', PCelt. *wriggant- 'worm, vermin', cf. MIr. frige, MW gwre, MBret. gruech), plants (e.g. PCelt. *subi- 'strawberry', cf. OIr. sub, MW pl. syui), and elements of the physical world (PCelt. *liro- 'sea', cf. OIr. ler, MW llyr, PCelt. *klukā 'stone, rock', cf. OIr. cloch, MW clog, Co. clog). ${ }^{4}$ Note that cognates of these words may be unattested in Gaulish and Celtiberian because these languages are poorly attested, so that the actual number of exclusive loanwords from substratum language(s) in Insular Celtic is probably even lower. In my opinion it is not higher than $1 \%$ of the vocabulary. The large majority of substratum words in Irish and Welsh (and, generally, in Goidelic and Brythonic) is not shared by these two languages, which probably means that the sources were different substrates of, respectively, Ireland and Britain; here we may mention such etymologically obscure words as OIr. sinnach 'fox' (W cadwo), OIr. luis 'rowan-tree' (W cerdinen), OIr. lacha 'duck' (W hwyad), ${ }^{5}$ OIr. lon 'blackbird' (W has aderyn du, the calque of English blackbird), OIr. dega 'beetle, chafer' (W chwilen, gordd), OIr. ness 'weasel' (W has gwenci, a compound of gwen 'white' and ci 'dog') $)^{6}$, MoIr. partán 'crab' (W cranc, probably from Lat. cancer), ${ }^{7}$ etc.

The source of these substratum words in Insular Celtic is completely mysterious. The natural place to look for them would be Afro-Asiatic and Basque, but it is quite certain that they were not borrowed from either of these languages. ${ }^{8}$ The possible Afro-Asiatic cognates seem to be lacking, and, while there are some Basque words that might be etymologically related to Celtic, the direction of the borrowing is by no means established. Thus, while it is generally assumed that Basque hartz 'bear' was borrowed from Celtic (OIr. art, MW arth < PIE * $h_{2} r t k$ 'o- 'bear', cf. Hitt. hartagga-, Gr. árktos, Lat. ursus, etc.), what should we think of the

${ }^{4}$ For an extensive list of these words see Matasović 2009: 441-443. To the words listed there we may also add the word for sea-gull (OIr. faílenn, MW gzylan, Bret. gouelan, OCo. guilan gl. alcedo, which Schrijver 1995: 115-116 hesitatingly connects to the root *way- in MW gwae, woe' and OIr. fáel, wolf'), the word for bat (OIr. íaltóc, íatlu, MW ystlum, stlum), periwinkle (MoIr. faochán, W gwichiad, MoCo gwihan - the Irish word may have been borrowed from Brythonic) and possibly a number of others.

${ }^{5} \mathrm{~W}$ hwyad is sometimes incorrectly derived from the PIE word for 'bird' (PIE * $h_{2} e w i->$ Lat. avis, etc.), which does not explain the initial $h$ - (Matasović 2009: 50).

${ }^{6}$ OIr. has also es, esóc with secondary loss of initial $n$ - which was assimilated to the article.

7 See Schrijver 2000, 2005 for a possible connection of this word with the (presumably pre-Irish) ethnonym Partraige.

8 There do not appear to be any Afro-Asiatic toponyms in the British Isles, either. Those proposed by Vennemann (1998a, 1998b) are not persuasive. For a survey of probable pre-Celtic toponyms in Ireland and Britain see Adams 1980. 
relationship between MIr. ander 'young woman', MW anneir 'heifer', Gaul. anderon (genitive plural, Larzac) and Basque andere 'lady, woman' (Matasović 2009: 35)? In my opinion, if the similarity is not accidental, it is equally possible that the Basque word was borrowed from Celtic as that the borrowing was in the opposite direction. Likewise, if there is any connection between Proto-Celtic *bostā 'palm, fist' (Matasović 2009: 71, cf. OIr. bos, MW bos) and Basque bost 'five' (perhaps from 'the number of fingers on a palm'), I believe that the Basque word was borrowed from Celtic, because the Celtic words can be plausibly connected to MHG quast 'branch', Alb. gjethe 'leaf, foliage', so that their IE etymology is probable. Finally, OIr. adarc 'horn' does not have any cognates in Brythonic, but Basque adar 'horn' appears very similar. If it is an early loan from Basque into Insular Celtic, the word final $-c$ in OIr. is unexplicable. If the direction of borrowing was from Celtic into Basque (or from some third language into both Goidelic and Basque) the root-final consonant(s) of the source may have been lost in Basque. But of course, like many Celtic-Basque parallels, this one is also very speculative.

There are several, perhaps many words of substratum origin shared by Insular Celtic (apparently more often Brythonic than Goidelic) and the other Celtic and Indo-European languages of Western Europe. These words were assembled and discussed by Peter Schrijver (see Schrijver 1997), e.g. W crychydd 'heron' vs. OHG reigaro, OE hrāgra 'heron', MW baed 'boar' vs. OHG bēr, OE bār (< PGerm. *baizo-), MW mwyalch 'blackbird' vs. OHG amsla, amasla, Lat. merula, OIr. lem 'elm', MW llwyf vs. OE elm, OHG elm-boum and Lat. ulmus. These may be from a non-IE substrate of the Central Europe, borrowed independently into Proto-Celtic, ProtoGermanic, and (some of them) into Italic languages. They do not, however, represent loanwords from the pre-Celtic substratum in the British Isles.

It could be argued that the substratum of Insular Celtic could be identified with AfroAsiatic because of the typological parallels between these two groups of languages, but that the Afro-Asiatic loanwords in Insular Celtic are lacking because of the specific nature of the language contact between their speakers. It is quite possible that there are loanwords that cannot be recognized as such, and we should not forget that intensive language contacts are possible even without massive lexical borrowing (Thomason 2001: 11, 63). ${ }^{9}$ In cases where the structure of the language makes it difficult for it to borrow new lexical items (e.g. if compounding is the default strategy for deriving new meanings), languages can co-exist side by side for centuries, and this will not be visible in their vocabularies. However, mutual influences can exert themselves in grammatical structure, especially if there is widespread pattern of bilingualism, e.g. if exogamy is the norm between two ethnically and linguistically different communities. Moreover, languages can be parts of the same Sprachbund (language area) and share a number of structural features if they are not spoken in areas adjacent to each other, i.e., if other languages belonging to the same Sprachbund intervene. We see this, for example, in the

9 "But the implications of loanword evidence are asymmetrical: the presence of numerous loanwords is a sure sign of contact with the donor language, but the absence of numerous loanwords does not necessarily point to lack of contact. Montana Salish, for example, has borrowed some words from English, but not very many; instead, when speakers want to refer in Salish to items borrowed from Anglo culture, they tend to construct new words out of Salish components. So, to take just one of many examples, the Montana Salish word p'ip'uysin "automobile" literally means "wrinkled feet" (or, more precisely, "it has wrinkled feet"), a name derived from the appearance of the tire tracks. In fact, this aspect of Montana Salish speakers' linguistic behavior may be an areal feature characteristic of the Northwest region of the United States and Canada; the Sahaptian language Nez Percé of Oregon, Idaho, and Washington also has few loanwords, and many years ago the great linguist Edward Sapir commented that Athabaskan languages tend not to borrow words from European languages (Thomason 2001: 11)." 
Balkans, where we do not find many loanwords from Romanian in Albanian (or vice versa), because a belt of South Slavic languages separates them. ${ }^{10}$ On the other hand, both languages are exemplary members of the Balkans Sprachbund, sharing such features as the lack of infinitive, postposed definite articles, clitic pronouns, etc.

However, such a scenario (long term bilingualism between languages in contact, with little lexical borrowing) is unlikely for the British Isles. Whenever the Celtic speakers arrived there, they were probably not numerous - there is hardly any archaeological evidence for large-scale migrations into Britain or Ireland in the Bronze Age and later (prior to Roman invasion). Thus, the elite dominance model, where the majority of the population adopts the language of a small group of immigrants, is more likely for the Celticization of the British Isles, and in such a situation we would expect the substratum languages to contribute more than just the syntactic patterns to the superstratum Brythonic and Goidelic. And indeed, this is probably what happened: it is just that there were many substratum languages when the Celts entered the British Isles, and the languages of those Celts were already differentiated by that time. A priori, the linguistic diversity in the British Isles before their Celticization is only to be expected. If we look at the linguistic map of Italy before the Roman conquests, we find that very many languages were spoken there, only some of which were Indo-European (Messapic, Venetic, and the Italic languages). Moreover, the non-IE languages of pre-Roman Italy (North Picene and Etruscan) were, in all likelihood, unrelated. There is no reason to assume that there was less linguistic diversity in Bronze Age Britain and Ireland than there was in Iron Age Italy.

\section{Conclusion}

The thesis that Insular Celtic languages were subject to strong influences from an unknown, presumably non-Indo-European substratum, hardly needs to be argued for. However, the available evidence is consistent with several different hypotheses regarding the areal and genetic affiliation of this substratum, or, more probably, substrata. The syntactic parallels between the Insular Celtic and Afro-Asiatic languages are probably not accidental, but they should not be taken to mean that the pre-Celtic substratum of Britain and Ireland belonged to the Afro-Asiatic stock. It is also possible that it was a language, or a group of languages (not necessarily related), that belonged to the same macro-area as the Afro-Asiatic languages of North Africa. The parallels between Insular Celtic, Basque, and the Atlantic languages of the Niger-Congo family, presented in the second part of this paper, are consistent with the hypothesis that there was a large linguistic macro-area, encompassing parts of NW Africa, as well as large parts of Western Europe, before the arrival of the speakers of Indo-European, including Celtic. The historical origin of this macro-area can be seen in the re-population of Western Europe after the last Ice Age from the Western Mediterranean, or in the much later spread of agriculture along the Atlantic coast, which was probably associated with the archaeological culture of megalithic tombs in NW Africa and the western fringes of Europe in the Neolithic and early Copper Age (Sherratt 1994). We will never know for sure. The existence of a number of typologically similar languages in Western Europe and North-Western Africa prior to the arrival of the Celts (and other speakers of IE dialects) in no way implies that they all belonged to a single linguistic stock, including Afro-Asiatic.

${ }^{10}$ Of course, there is a layer of extremely old and numerous Latin loanwords in Albanian, and Romanian also contains a number of non-Slavic and non-Romance substratum words, some of which are also attested in Albanian. 
Finally, the fact that there appear to be only a few words of non-IE origin shared by Goidelic and Brythonic, but not by other Celtic or Indo-European languages, points to the conclusion that Proto-Insular Celtic was not the language spoken by the Celts who first came into contact with the pre-Indo-European inhabitants of the British Isles. As far as the evidence of these loanwords is concerned, Proto-Insular Celtic never existed.

Tatyana A. Mikhailova

Moscow State University

Once again on the pre-Celtic substratum in the British Islands

A compact paper by the well-known Indo-European and Celtic scholar Ranko Matasović deals with, essentially, three different problems, each of which is extremely complicated and, from the perspective of Celtic studies, hardly suggests a simple and unequivocal solution. Thus, in his introduction he remarks that it is nearly impossible to identify which kind of language - either typologically or genetically - had been spoken on the British Isles before Celtic occupation (the very fact that an unknown pre-Celtic population certainly did exist is indicated by multiple archaeological discoveries, some of which show parallels between Britain and Ireland). However, already in the next phrase Matasović shifts his attention to the old and painful problem of the Pictish language, stating that "it may actually have been Celtic", with a reference to a single concise book by K. Forsyth (Forsyth 1997). Forsyth is, first and foremost, an archaeologist rather than a linguist; second, she is somewhat aware of the fact that her straightforward claim to have identified the Pictish language as Celtic is grossly oversimplified, and, consequently, suggests that linguists might solve the problem by looking from a different angle.

Yet Pictish is actually irrelevant here, because, whatever known family it belonged to - along with the Pretanic theory, there have been claims of identifying Pictish as Basque, Germanic and Proto-Saamic - it would hardly give us the answer to the question of what language had been spoken on the British Isles in the pre-Celtic era, that is, before the mid-2nd millennium BC, which is the earliest likely time of Celtic invasion into the region. The Picts, who inhabited a rather limited area of southeast Scotland (and perhaps northeast Ireland as well) could easily have belonged to a later migration wave. Thus, other lands may have been inhabited by people (or peoples) speaking a different language (or languages). Thirdly, and finally, the problem of pre-Celtic substratum in Insular Celtic languages is directly linked, or at least related, by Matasović to another complex problem that does not have an unambiguous solution problem - that of constructing the genealogical tree for Celtic languages. More specifically, he raises the question of whether the very possibility of explaining the peculiarly Insular Celtic traits in these languages could depend on a particular scholar's adherence to either the «GalloBrittonic» or the «Insular» theory.

This kind of approach at first seems to be almost scandalizing, since one hardly can see the Insular theory as having anything to do with the issue of substratum. Indeed, the theory according to which "the Brittonic of the Roman Period was in fact the local British variant of Gaulish" (Schmidt 1980: 179), after having been accepted uncritically for a long time, has been severely criticized during the last decades. As an alternative option, the Insular Celtic theory was constructed, which suggested an original affinity between the Goidelic and Brittonic branches of the Celtic language family, thus inevitably dismissing the 'P Q' subgrouping model for Celtic languages. ${ }^{11}$ Certainly, some phonetic fluctuations attested within Gaulish dialects (that is, between the $2^{\text {nd }}$ century BC and $2^{\text {nd }}$ century AD) indicate that this conventional model is somewhat artificial and that the shift ${ }^{*} q^{w}>p$ is a relatively late phenomenon. However, the proponents of Insular theory rely just as much on the evidence from historical phonology. Besides, as John T. Koch soundly

${ }^{11}$ Reflexes of IE ${ }^{*} q^{w}$. 